\title{
The Role of Visuals in Language Learning and Instructions
}

Asst. Lecture: Husam Ahmed Abbood

Imam Kadhum College for Islamic Science

\begin{abstract}
A single image can stand for complex idea. We might spend an hour reading an article about the divorce effect on children and destruction of the family. But a photograph of a child crying between two hands of his parents evokes in us an instant emotional response. While both the articles and the photographs communicate the magnitude of the damage that divorce can cause, the power of an image allows us to understand this message within nanoseconds. The study is focused on the ability of image in eliciting language across all the four skills: listening, speaking, reading, and writing in the instructional strategies which may definitely enhance students' critical thinking skills. Besides, this research offers one strategy which is adapted from an online lesson at the National Archives and Records Administration NARA for integrating visual literacy into language instruction. thereby transforming a language lesson into one that meets the goals of the content classroom as well.
\end{abstract}

Key words: visual literacy, Critical thinking skills, instructional strategies.

\section{Introduction}

Indeed, many research that dealing with the image processing especially cognitive research has shown that the human brain processes images quicker than it processes words, and images are more remain in our long-term memory more likely text (Levie and Lentz 1982: 195-232). With the modern technology and its expansion that allows people to create and share photographs with a few clicks, and the direction to value visual media seem to be more than ever before in the world.

As a teacher of language, what if we go slowly with this image-viewing process to unpack what the behind the pictures which can be thousand of words that? We may be attract of the formation of the textual demands of instructional material, syntax, vocabulary and discourse, and so on-then glancing at pictures as supportive (compliment) items to text passages.

"There is an old saying that a picture is worth a thousand of words. When it comes to comprehension, this saying might be paraphrased, a visual display helps reader understand, organize, and remember some of those thousand words" (Duke \& Pearson 2002). This article pays more attention to the image and put it at the forefront of instruction, considering the possibilities that visual media offer for language learning. Instead of regarding pictures as no more complementary to text, the ability of image in eliciting language across all the four skills: listening, speaking, reading, and writing. This incorporation of images in language instruction will tempt and appeal to digital native learners, those students who emerging and developing economies in a world where using technology such as smart phones, laptops, and social media is part of everyday life (Prensky, 2001).

Those digital natives' students are not intuitively adept at criticizing and analyzing images skills that can be considered part of visual literacy. Knowing how to upload images from the smart-phones to social programs like Facebook or Instgram does not make any person visually literate. However, and critiquing images, (Brumberger, 2011: 19-47). 
There are so many underlying messages which the creators may consciously or unconsciously convey. But we already missed them because of the passive consuming of images in the media.

Communicative language classrooms are an ideal location to cultivate the visual literacy skills involved in viewing and creating images. In this article, I describe ways to use images to support students' language skills while honing their abilities to analyze and create messages; sophisticated technology or high-resolution cameras are not required. I first summarize ways educators have defined visual literacy, provide a rationale for connecting visual literacy to the language classroom, and then give examples of instructional techniques with photographs.

\section{Objectives of the study}

The study aims to highlight the impact of using visual literacy such as images in instruction and communication on students' academic achievement. It shreds the light of the effect of images skills that can be considered part of visual literacy which help better interpret art and visual that they contact with.

\section{Significance}

The importance of the subject study is a result of the following issues:

1- It develops the student's abilities of analyzing the visuals to unpack what the behind the images which can be thousand of words.

2- It encourages both teacher and student to use the visual literacy to explore the underlying messages which the creators may consciously or unconsciously convey.

3- It allows reaching a simplified strategy which leads to easy understanding and deeper interactions with texts of all kinds and introduces the process of analytical thinking about representation and meaning.

\section{What is visual literacy?}

The archaeologists before so many years and until this moment uncovering hieroglyphics can attest, using images to create and interpret messages and that has distinguished humans from other living things since the dawn of civilization (Burmark 2002).

The term visual literacy, however, did not appear in education literature until 1969, when Debes (1969: 25-27) first coins the concept as a set of competencies that "a human being can develop by seeing and at the same time having and integrating other sensory experiences"

Visual literacy, he writes, " refers to a group of visioncompetencies... when developed, they enable a visually literate person to discriminate and interpret visible actions, objects, symbols, natural or manmade, that he encounters in his environment. Through the creative use of these competencies, he is able to communicate with others "

Debes argued that these visual competencies enable individuals to communicate with others, establishing a clear connection between visual literacy and language education.

On the other hand, Felten (2008: 60-63) echoes this belief stating 
"Visual literacy involves the ability to understand, produce, and use culturally significant images, objects, and visible actions. . . . With training and practice, people can develop the ability to recognize, interpret, and employ the distinct syntax and semantics of different visual forms. The process of becoming visually literate continues through a lifetime of learning new and more sophisticated ways to analyze and use images."

In the course of recent decades, researchers and experts from a variety of fields have conceptualized visual literacy, offering points of view going from theoretical to pragmatics (Schiller 1987).

Later on, (Dr. Diana Dumetz) defines the visual literacy as the ability to decode, interpret, create, question, challenge and evaluate texts that communicate with visual images as well as, or rather than, words. Visually literate people can read the intended meaning in a visual text, interpret the purpose and intended meaning, and evaluate the form, structure and features of the text. Thus, the nonattendance of a typical definition recommends the unpredictability of the procedures required in interpreting and creating visual messages. For the reasons for this article, I assume a moderately broad meaning of the term that reflects fundamental ideas from the literature: visual literacy is the competency to make significance from what we see and to create pictures that implicit and explicit message to others.

Maria Ebner \& Derek Bruff (2010) describe the power of visual tools to enhance the visual thinking as they mention that "Our brains are wired to rapidly make sense of and remember visual input. Visualizations in the form of diagrams, charts, drawings, pictures, and a variety of other ways can help students understand complex information. A well-designed visual image can yield a much more powerful and memorable learning experience than a mere verbal or textual description"

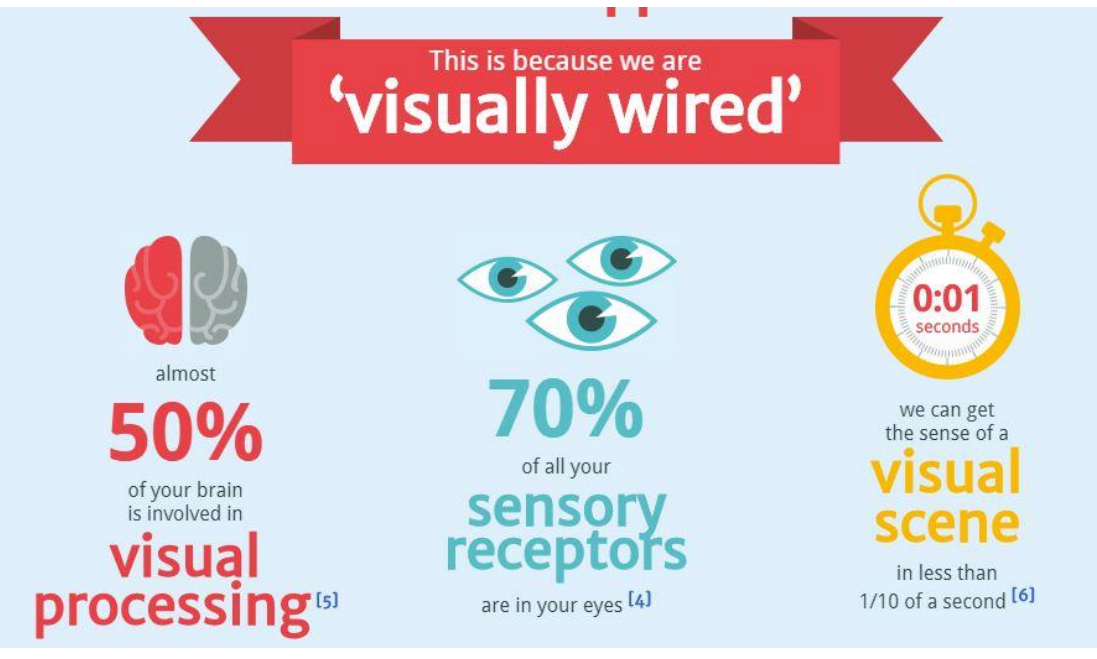

Figure (1)

\section{Connecting visual literacy with language learning}

In my work as an English language teacher of ESL, I find these images have played a critical part if not essential. Images are sometimes used to support comprehension, as a platform tool to help students rapidly connect unfamiliar words with concepts (Beck, McKeown, and Kucan 2002). However, images are also push the students to broaden their capacities, 
therefore, while visual literacy can be coordinated with various content areas, powerful activates with images make an effective contribution to language learning.

\section{Meaningful oral interaction}

Stimulating linguistic production can be exploring obviously by images. The way we interpret images depends on our stored information or schema, a background knowledge and past experience to each of us. Since the interpretation of what we see is subjective, analyzing pictures will let to provide chances for meaningful student to students interaction. By using images in the ESL classroom, challenge students to evoke and share the feelings that an images express, by like or dislike particular images. This kind of expressing is truly communicative

\section{Critical thinking skills}

There only one way to understand an image and expressing opinions takes unlimited forms. Analyzing and interpreting images requires skills high on Bloom's (1956) taxonomy, such as synthesizing, evaluating and analyzing. That is often called "critical thinking skills," Bloom's higher-order skills are important when communicating abstract ideas through language. Visual literacy activities can help students sharpen these skills. For example, instructional strategies that enhance visual literacy call for open-ended questions, such as those starting with "Why" and "What if," that requires extended reactions and higher thinking abilities. Justifying why they understand images in certain ways requires students to break down the image and analyze these bits before producing a response based on evidence from the image. Expressing that one "likes" or "dislike" an image is not adequate for visual literacy; instead, students are challenged to connect vocabulary from the visual representations with past experience or an abstract ideas.

\section{Global perspectives of the images}

Image can tell thousands of words, in educational platform, it's provide a means for students to interact with phenomena from across the world; different perspectives occurs in seconds by observing images and can be done by learners of all language levels. But there is real value in using images to promote scientific content. And perspective taking, from one person to another, is associated with language acquisition and development (MacWhinney 2005:198-223)

Images compel the viewer to monitor objects framing by the camera. Comparing different forms of the same image foster students' recognition that an object can be shown in different ways, not unlike the way a concept can be expressed using different languages. Images enable students to understand objects not only from varying locative perspectives, but also to examine and explore visual motives from different global perspectives.

\section{The power of scaffolding}

One of the Burner's principles of his known theory "Constructivist Theory" describes as "Instruction should be designed to facilitate extrapolation and or fill in the gaps (going beyond the information given)" (1973). In the educational process, using images can serve as a type of instructional scaffolding, the construct described as a fundamental support for inspiring and facilitating tasks beyond the independent capability of the student. Images can be used as an intermediary support for students who have not yet mastered particular vocabulary or sentence structures. For instance, teachers might refer to photographs or icons when introducing new topics or vocabulary so that students quickly grasp the meaning of new terms. Using graphic organizers to spatially represent conceptual relationships is another 
example of support in language activities. Research shows that students who utilize these kinds of visual aids perform better on language tasks than those who do not (Baratta and Jones 2008; Nunan 1999). Importantly, though, scaffolding mechanisms are by definition temporary; the supports should eventually be removed as students gain more proficiency and are able to complete tasks independently. The goal is not to eliminate visual elements from instruction, but instead to change gradually the ways students use images as supports. For instance, beginning language learners might move from making single word utterances to labeling items in a photograph to forming complex sentences that make inferences about the context of the photograph.

\section{Linking language with content}

The activities of visual literacy also provide an opportunity to connect language to content (e.g., science, math, social studies). Researcher have always called for language education to be linked to the content whether by structured instructional program, such as integrated learning (Coyle, Hood, and Marsh 2010) or simply by using thematic topics that are meaningful for students. Since we are dealing with content and try to enhance it, using images is one way to do that in the classroom, by interacting with language to communicate about certain concept rather than memorizing and committing to grammar or vocabulary which might seem arbitrary. Images are considered form of authentic material. So, as educators purposely choose texts they use in the classroom, they have to pay attention in selecting images that strategically match the content learning goals. Content material can be integrated into any of the strategies described in this article, thereby transforming a language lesson into one that meets the goals of the content classroom as well.

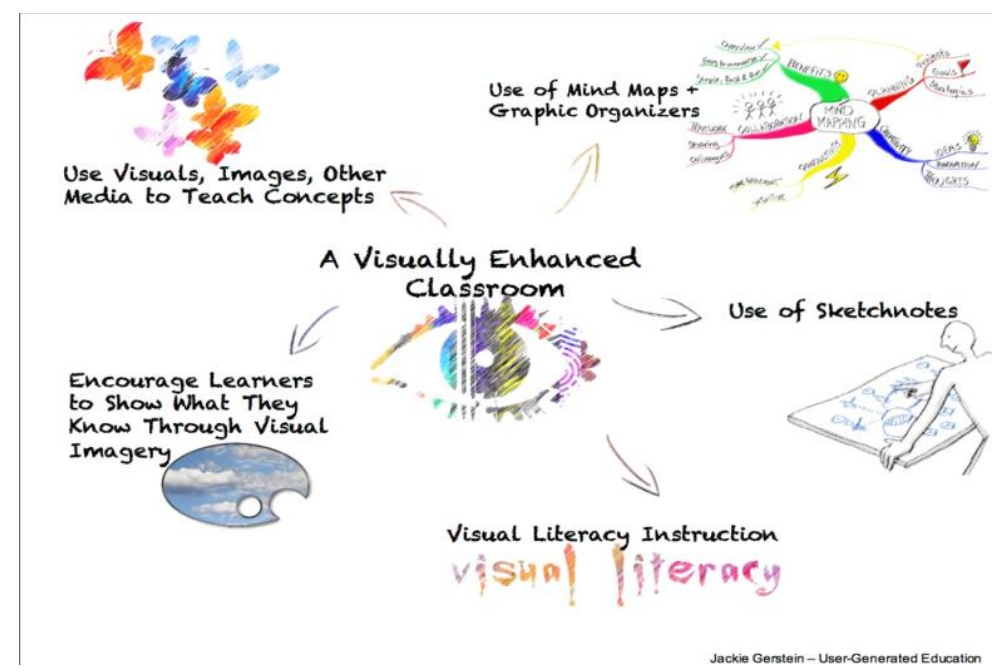

Figure 2 taken from https: // usergeneratededucation.wordpress.com

Next, I describe one strategy for merge visual literacy into language instruction, which is adapted from an online lesson at the National Archives and Records Administration (www. archives.gov/education/lessons). The only required materials for the activities are photographs.

\section{Instructional Strategy using visual image}

\subsection{Photo Analysis Strategy:}

The practice of using image in the classroom, then analyzes it, will facilitate some student's skills such as observation skills and challenging them to identify and use language that is part of the image used. The below strategies, which is adapted from an online lesson at the 
National Archives and Records Administration (www. archives.gov/education/lessons), work better with group of four students.

\subsubsection{Preparation}

Select one image for each group, the image is belongs to an event or occasion that is familiar to the students. All groups can work with the same image, or different image can be contributed to each group. Printing copies of the images will ease the process which allows each student get his / her own copy. Three columns are important to have, they can make them by themselves or the instructor can create for them. The columns are: (Peoples), (Things) and (Actions). Then apply the following steps:

\section{a. Discuss the overall impression}

This will accomplish by discussing their initial impression of the photograph. To guide discussion, you can ask questions such as:

What is going on in this photograph?

What is this photograph about?

How does this photograph make you feel?

In this step, students will have different and even contrasting opinions. Encourage groups to jot down all representative ideas. Forming a holistic impression does not need to take longer than five minutes, but discussing the photograph as a whole ensures that students have a clear context of the photograph before they focus on details.

\section{b. Observe closely}

Divide the image into four parts. Assign one student in each group to a part. Students might hide the other parts of the image with a blank piece of paper so they can focus particularly on their assigned parts.

\section{c. List}

Students may begin to list by filling the three-column chart to people, things, and actions they see in their part. Try to Challenge them to list as many items as they can.

\section{d. Share}

Each student will observe his part of the image separately, so the Students can share the items on their list with their group members. Then, the list will be different.

\section{e. Compare parts to the whole}

Students then return to their initial impressions. They discuss whether their list support or not support these impressions. Instruct students to $*$ identify items on your list, * support your initial impression, or * use your list to tell why you had your initial impression. * Viewing an image holistically and then moving to an examination of details gives student's opportunities to defend ideas with examples and to practice critical thinking skills.

\section{f. Make inferences}

Considering the compiled lists and the former impressions, students in each group agree on three inferences they can make about the image. Each inference must include justification based on the people, things, or actions they observe in the image. To make this justification about the inferences, students will use the vocabulary they note on their three-column list. 
This is an opportunity to help students understand how to infer and what an inference is. Also, explain that the inferences are based on observable facts (e.g., items on their lists) and can also involve invisible assumptions. a fact that may be part of students' background knowledge.

\section{g. Pose questions}

Lastly, listing open-ended questions based on the photograph raises extend the students thinking. These should be questions that are not easily answered by only looking at the exterior of the photograph, but instead require additional investigation about the context of the photograph. Such questions that begin with "What if ... and "Why ..." or."

\subsection{Other recommendation and support}

There are a lot of activities and methods that enable us to use images in the teaching process to raise the student's mental efficiency. The teachers can use the kind of image that has a secret or ambiguity to reveal. This strategy helps students how to make guesses and also engages students in inductive reasoning, providing an element of suspense that involves the language of prediction. In making these guesses, students practice using the language of prediction (e.g., "I predict that it will be ..." or "I think it will be ...") as well as vocabulary associates with the photograph. With a large class, rather than calling on only one or two students to share, ask students to talk with a neighboring student about their predictions. Such pair work ensures that all students are engaged and using the predictive language.

After the step of guessing and get the final reveal of the image, This kind of discussion involves meta cognition, To facilitate this discussion, ask questions such as, "At what point could you identify the photograph's content?" . A debriefing conversation also allows students to discuss how seeing only a piece of a picture often gives different connotations and perspectives than seeing the photograph in its entirety.

When describing pieces of the photograph, students with beginning English proficiency may use one- or two-word utterances; more advanced students can be challenged to use complex sentences. Students might also move from describing concrete objects in the photograph to expressing subjective impressions of each part, such as feelings or memories that the images provoke.

\section{Conclusion}

Educators emphasize the important of the authentic learning experiences for English learner. They try their best to make the activities in the language class are effective by replicate the kinds of interactions that students encounter outside the classroom such as instragm, smart phones and social network programs. Between all these applications, images play essential role in the students' lives.

Considering the essential role of the image in language learning in the students' lives, we can draw several activities upon images to elicit communicative language from students such as those describe in this research. As students become familiar with ways to talk about images, visual literacy can be integrated into daily classroom routines. Rather than a stand-alone lesson, discussions about photographs can occur regularly to enhance other learning.

To conclude, we have to return back to the saying that "A single image can stand for complex idea" which many researchers and experts from a variety of fields conceptualize and recognize the potential that photographs have to elicit meaningful conversation. Considering 
the powerful and effective scaffolding in language learning and instruction, students need to understand the way visual language works to convey meaning. We must help our students think critically about the images that make up their world. Many of the same strategies used to make sense of print, can be used to understand a visual text. Like print, visual language has its own genres, features, codes and conventions. All of which work together in the construction of meaning. The strategy described in this research cultivates reflective students who are able to "look into" photographs by eliciting deep thinking, creativity, and advanced language. Along with trying out this strategy, it is challenging time for educators to hone the observation skills, looking for ways to take advantage of the language-use possibilities that lie. Therefore, this study confirms the importance of the research which is:

1- It develops the student's abilities of analyzing and (look into) the visuals to unpack what the behind the images which can be thousand of words.

2- It encourages both teacher and student to use the visual literacy to explore the underlying messages which the creators may consciously or unconsciously convey.

3- It allows reaching a simplified strategy which leads to easy understanding and deeper interactions with texts of all kinds and introduces the process of analytical thinking about representation and meaning.

\section{REFERENCES}

Baratta, A. and S. Jones. 2008. Using film to introduce and develop academic writing skills among UK undergraduate students. Journal of Educational Enquiry 8 (2): 15-37.

Beck, I. L., M. G. McKeown, and L. Kucan. 2002. Bringing words to life: Robust vocabulary instruction. New York: Guilford.

Bloom, B. S., ed. 1956. Taxonomy of educational objectives. Handbook 1: Cognitive domain. White Plains, NY: Longman.

Brumberger, E. 2011. Visual literacy and the digital native: An examination of the millennial learner. Journal of Visual Literacy 30 (1): 19-47.

Bruner, J. S. 1975. From communication to language: A psychological perspective. Cognition 3 (3): 255-287.

Burmark, L. 2002. Visual literacy: Learn to see, see to learn. Alexandria, VA: Association for Supervision and Curriculum Development.

Coyle, D., P. Hood, and D. Marsh. 2010. CLIL: Content and language integrated learning. Cambridge: Cambridge University Press.

Debes, John. 1969. The Loom of Visual Literacy. In: Audiovisual Instruction. 14 (8), 1969: 25-27.

Diana Dumetz Carry, Visual Literacy: Using Images to Increase Comprehension, retrieved at 14/Aug/2017 from https://readingrecovery.org/images/pdfs/Conferences/NC09/Handouts/Carry Visual Literacy.p $\underline{\mathrm{df}}$

Duke, N. K., \& Pearson, P. (2002). Effective Practices for Developing Reading Comprehension. International Reading Association

Felten, P. (2008). Visual literacy. Change. Nov./Dec. 2008: 60-63. 
Jackie Gerstein. Schools Need to Include More Visual-Based Learning. Retrived on 14/Aug/2017 from https://usergeneratededucation.wordpress.com/2015/07/11/schools-need-to-include-morevisual-based-learning/

Levie, W. H., and R. Lentz. 1982. Effects of text illustrations: A review of research. Educational Communications and Technology Journal. A Journal of Theory, Research, and Development, v30 n4 p195-232 Win 1982

MacWhinney, B. 2005. The emergence of grammar from perspective. In Grounding cognition: The role of perception and action in memory, language, and thinking, ed. D. Pecher and R. A. Zwaan, 198-223. Cambridge: Cambridge University Press.

Maria Ebner \& Derek Bruff. Visual thinking. A preview of "Show and Tell: Visual Thinking in the Classroom," a workshop at the Vanderbilt University Center for Teaching's January 2011 conference for grad students, GradSTEP 2011. Retrieved on 14/Aug/2017 from https: / / fft.vanderbilt.edu/guides-sub-pages/visual-thinking/.

National Archive. Educators Recourses. Teaching with documents, retrieved on 1/Sep/2017 from https://www.archives.gov/education/lessons

Nunan, D. 1999. Second language teaching and learning. Boston: Heinle and Heinle.

Prensky, M. 2001. Digital natives, digital immigrants. On the Horizon (MCB University Press, Vol. 9 No. 5, October 2001)

Schiller, H. A. (1987). Visual literacy in ancient and modern man (part one). In R. A. Braden, D. G. Beau- champ, \& L. W. Miller (Eds.). Visible \& Viable: The Role of Images in Instruction and Communication. Commerce: East Texas State University. 